confine itself to the creation of practice and knowledge. It also makes sweeping, and at times flamboyant, Last Judgements about scientific practice and knowledge as a whole, as in the concluding chapters of The Golem $^{5}$ and Constructing Quarks ${ }^{2}$. It is this aspect of the SSK literature that is our first concern, for these judgements can be 'understood' by laymen and

schoolchildren, whereas the technical parts of the case studies cannot.

As to prediction, of course "later predictive success cannot be appealed to as a cause of earlier acceptance". We made no such appeal in bringing up chaotic motion in the Solar System and the Planck spectrum of the cosmic background radiation, which were discovered long after classical mechanics and the quantum theory had become firmly accepted. They are among many examples that illustrate the astonishing (and mysterious) ability of science to account for phenomena of which no inkling was available when the relevant theories were first accepted. The SSK literature is biased because it does not include case studies of such episodes, nor of experiments that test established theory to high accuracy.

Rather, it devotes great attention to two other topics: first, to the undeniable fact that scientific practice and knowledge rarely conform to any known set of philosophical ground rules; second, to features of scientific knowledge that are common to knowledge as a whole. Such commonalities abound; scientific knowledge is generated in ways that have typically human characteristics. But the end product is very different from those of virtually all other human activities.

SSK argues that scientists make choices contingent on culture. There is truth to this. But if that were all - if there were as much freedom to choose as SSK claims - a good portion of the major theories whose acceptance had been successfully 'negotiated' should fail disastrously in regimes where they were supposed to work, as popular policies often do in a democracy. Why scientific knowledge is, in contrast, so robust is not explained by the canon of SSK.

Collins and Pinch say that the "evaluation of scientific findings is not our business" (a position they share with Bloor and MacKenzie). Pickering, in contrast, evaluates the findings of particle physics in part as a former professional particle physicist with his own unusual scientific views (see pages 250-252 of ref. 4).

Constructing Quarks is a "best, empirical, case-study", to use Bloor and MacKenzie's term. Nevertheless, having been active participants in the move to the new physics, we disagree with Pickering's conclusion that "objective merit" was not

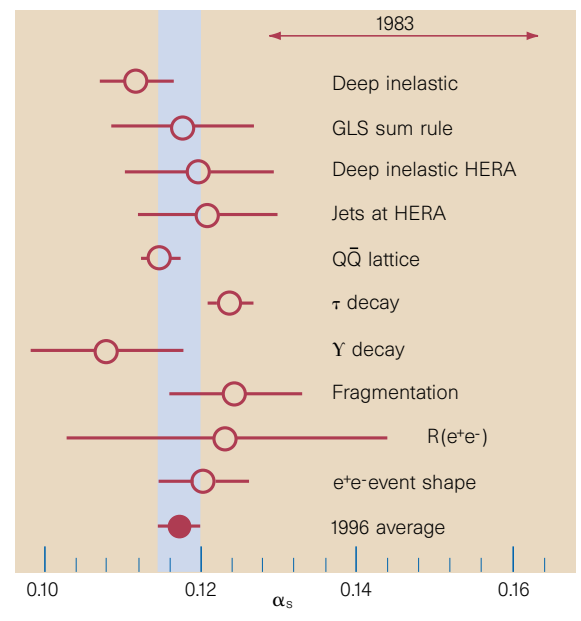

There were two errors in the figures in Gottfried and Wilson's article ${ }^{1}$. The corrected Fig. 1 (above) illustrates the coupling constant $\left(\alpha_{\mathrm{s}}\right)$ of QCD as determined today from various experiments and calculations, compared with the range of values determined in 1983. The term "Fragmentation" was incorrectly labelled “1983”. In Fig. 2, the green line referred to in the caption was incorrectly printed blue.

"what induced most physicists to move". Indeed, consider the following statement in Pickering's account (see page 411 of ref. 2): "...the world of the old physics was conceptually and socially fragmented. Traditions organized around different phenomena generated little support for one another.... With the advent of the new physics, the conceptual unification of forces was accompanied by a social unification of practice. The quark-gauge theory world view was at the heart of a community-wide symbiosis of experiment and theory."

As our essay explained, we agree with an edited version of this statement; the old physics was fragmented because there were few theoretical connections between its various models and recipes, whereas the new was a powerful theory that provided a unified account and unambiguous predictions, some of which were quickly confirmed. Pickering means his statement to be read as saying that unification was primarily a social phenomenon, "a communal search for a congenial world: a world in which practice could be socially organized", and it is this claim that underlies his final verdict against the objectivity of modern science.

Finally, to Capasso's excellent letter. We set technology aside because we could not do justice to it in the space allotted. Technology plays an essential role as both input and output in the processes of continuous improvement of scientific practice and knowledge after a theory is born, a topic to which SSK gives little notice. This is part of a larger problem we often encounter in the SSK literature: an inadequate description of the culture of physics - of the conceptual, historical and technological context in which research in modern physics is actually done.

\section{Kurt Gottfried}

Laboratory of Nuclear Studies,

Cornell University,

Ithaca, New York 14853, USA

Kenneth G. Wilson

Smith Laboratory,

Ohio State University,

Columbus, Ohio 43210, USA

1. Gottfried, K. \& Wilson, K. G. Nature 386, 545-547 (1997).

2. Pickering, A. Constructing Quarks: A Sociological History of Particle Physics (Univ. Chicago Press, 1984).

3. Gottfried, K. Physics Today 50, 61-62 (1997).

4. Pickering, A. The Mangle of Practice: Time, Agency, and Science (Univ. Chicago Press, 1995).

5. Collins, H. M. \& Pinch, T. J. The Golem: What Everyone Should Know about Science (Cambridge Univ. Press, Cambridge, 1993).

\section{Patents and royalties}

Sir - Philippe Ducor points out in his Commentary (Nature 387, 13-14; 1997) that due to "the wise licensing policy of non-exclusivity and modest pricing adopted by the owner (Stanford University), [recombinant DNA] technology was widely distributed and contributed enormously to the subsequent development of commercial biotechnology. However, the outcome would have been radically different if Stanford had chosen instead a restrictive licensing strategy... or granted no licences."

This is true. But this policy was set carefully so as to generate the largest possible return without causing the patent to be contested. Companies wishing to use the technology weighed the cost of royalties against the cost of a suit and eventually all decided it was cheaper to pay royalties. If one of the other options suggested had been taken, it is likely that the patent would have been contested and there is a significant probability that the patent would have been ruled invalid.

Stanford and the University of California have already gathered hundreds of millions of dollars in royalties on this basic patent, despite the "modest pricing". The work that gave rise to this technology and its key patents was paid for by ordinary people through their tax dollars used for basic research. Ordinary people have subsequently had to pay many times over the original investment through patent royalties. Should people be penalized for having spent tax money wisely in the first place?

\section{Robert B. Helling}

Department of Biology,

University of Michigan,

Ann Arbor, Michigan 48019-1048, USA

e-mail: Helling@biology.lsa.umich.edu 